Beek, A.P.A. van, Wagner, C., Frijters, D.H.M., Ribbe, M.W., Groenewegen, P.P. The ties that bind? Social networks of nursing staff and staff's behaviour towards residents with dementia. Social Networks: 2013, 35(3), 347-356

\begin{tabular}{|l|l|}
\hline $\begin{array}{l}\text { Postprint } \\
\text { Version }\end{array}$ & 1.0 \\
\hline Journal website & http://www.sciencedirect.com/science/article/pii/S0378873313000270 \\
\hline Pubmed link & \\
\hline DOI & $/ 10.1016 /$ j.socnet.2013.03.006 \\
\hline
\end{tabular}

This is a NIVEL certified Post Print, more info at http://www.nivel.eu

\title{
The ties that bind? Social networks of nursing staff and staff's behavior towards residents with dementia.
}

\author{
AdRIANA P.A. VAN BeEK ${ }^{\mathrm{A}, *}$, CORDUla WAGNER ${ }^{\mathrm{A}, \mathrm{B}}$, DinNus H.M. FrIJTERS ${ }^{\mathrm{C}}$, MIEL W. \\ RIBBE $^{\mathrm{C}}$, PETER P. GROENEWEGEN ${ }^{\mathrm{A}, \mathrm{D}, \mathrm{E}}$. \\ ${ }^{a}$ NIVEL: Netherlands Institute for Health Services Research, PO BOX 1568, 3500 BN \\ Utrecht, The Netherlands \\ ${ }^{\mathrm{b}}$ EMGO+, Department of Public and Occupational Health, VU University Medical Center, \\ Van der Boechorststraat 7, 1081 BT Amsterdam, The Netherlands \\ ${ }^{c}$ EMGO+, Department of Nursing Home Medicine, VU University Medical Center, Van der \\ Boechorststraat 7, 1081 BT Amsterdam, The Netherlands \\ d Utrecht University, Department of Sociology, PO BOX 80.115, 3508 TC Utrecht, The \\ Netherlands e Utrecht University, Department of Human Geography, PO BOX 80.115, \\ 3508 TC Utrecht, The Netherlands
}

\begin{abstract}
A B S T R A C T.
This study investigated social networks of nursing staff and staff's behaviour towards residents with dementia. We focused on two types of networks: communication networks among staff, and networks between nursing staff and relatives/acquaintances of residents. Data was collected in 37 long-term care units in nursing- and residential homes in the Netherlands.

In units with more networks between nursing staff and relatives of residents, staff treated residents with more respect and were more at ease with residents. Social networks were also positively related to staff's organizational identification which, in turn, related to their work motivation and their behaviour towards residents.
\end{abstract}

\section{INTRODUCTION}

Attitudes and behaviours of nursing staff towards patients are an essential aspect of quality of care in health-settings (Lothian and Philp, 2001; Boscart, 2009). Treatment of elderly patients is particularly important in long-term care settings. Because of their prolonged stay and health problems elderly residents in long-term care are extremely vulnerable and find themselves in an asymmetrical relationship with the nursing staff (Nelson, 2000). This is especially true for elderly residents with cognitive disorders such as dementia. Several studies have shown the importance of 
Beek, A.P.A. van, Wagner, C., Frijters, D.H.M., Ribbe, M.W., Groenewegen, P.P. The ties that bind? Social networks of nursing staff and staff's behaviour towards residents with dementia. Social Networks: 2013, 35(3), 347-356

good verbal and non-verbal communication skills of nursing staff in dementia care (Rundqvist and Severinsson, 1999; Perry et al., 2005).

Yet, controlling and directive behaviours of nursing staff towards elderly occur frequently (Hewison, 1995). Nursing staff in nursing homes often only communicate with residents with dementia during care-activities and then they predominantly give instructions and orders (Van Bilsen et al., 1998; Christenson et al., 2011). In addition, nursing staff cannot always understand the communication of residents resulting in low quality interaction (Van Bilsen et al., 1998), leaving nursing staff with feelings of frustration and helplessness (Pursey and Luker, 1995; Graneheim et al., 2001).

Long-term care can be characterized by the extreme frailty of its patients and an educationally diverse staff (Scott et al., 2004). In this particular setting, communication and teamwork between nursing staff are found to be important for quality improvement (Scott et al., 2004), and more open communication between nursing staff seems to be related to better resident outcomes such as mobility (Anderson et al., 2003). Contacts between nursing staff and relatives of residents are also deemed important for both care processes and outcomes for residents (Bluestein and Latham-Bach, 2007). However, at the moment it is still unclear how communication among nursing staff and between nursing staff and relatives of residents are related to care processes and through which mechanisms they influence quality of care.

In this article, we study care processes in long-term dementia care from a social network approach. We look at communication networks among nursing staff and networks of nursing staff with relatives and acquaintances of residents, and investigate how these networks are related to nursing staff's treatment of residents.

\section{THEORETICAL BACKGROUND}

Krackhardt and Hanson (1993) define communication networks as the informal networks of employees who talk about workrelated matters on a regular basis. Ties between nursing staff and relatives and acquaintances of residents cross the boundary of the organization. In line with Reagans and Zuckerman (2001), we name these ties boundary-spanning or boundary-crossing networks because they place employees in direct contact with third parties outside the organization.

Networks are often described by the density of interpersonal ties of its members, where density is seen as a measure of social cohesion (Friedkin, 2004). Since Seashore's classical study (1954) there have been multiple studies that link cohesion of networks to group outcomes (see Lott and Lott, 1965; Evans and Dion, 1991). Yet, results remain inconclusive, partly because conceptualizations of social cohesion differ greatly (Friedkin, 2004). Festinger (1950) first proposed that social cohesion should be seen as the causal system that determines individuals' membership attitudes and behaviours (see Friedkin, 2004). In this manner, conditions at the group-level can be seen as antecedents of attitudes and behaviour of groupmembers at the individual level (Friedkin, 2004). Over the years, several mechanisms are named through which networks influence behaviour of group-members. First, density of networks is believed to enable information exchange between actors. Granovetter (1973) first identified the strength of weak ties: low density networks of socially distant actors are more effective in 
Beek, A.P.A. van, Wagner, C., Frijters, D.H.M., Ribbe, M.W., Groenewegen, P.P. The ties that bind? Social networks of nursing staff and staff's behaviour towards residents with dementia. Social Networks: 2013, 35(3), 347-356

information exchange and innovation than high density networks of closely knit actors (Flache and Macy, 1996). Burt (1992) argued that a network in which a person has contacts with few others who provide unique information (a network with structural holes) is more productive than a network in which one has contacts with many others who provide the same information. Low density networks seem to be especially efficient for information exchange in more competitive work-settings. Tasks that depend on cooperation on the other hand seem to profit from networks with a high density (Flap and Völker, 2001).

Second, cohesive networks are deemed to affect trust between actors. Buskens and Raub (2002) name two aspects through which socially embedded relations affect trust: earlier experiences with actors (learning) and possibilities to sanction untrustworthy actors (control). Control in a social network can be the result of direct sanctioning between actors, but can also be the result of sanctioning by third parties and may even lead to social isolation if untrustworthy behaviour is detected. Research of control has mainly focused on its positive effects. However, Flache and Macy (1996) also name a negative effect of social cohesion, or - as they name it - a weakness of strong ties. They argue that relations between two group-members evolve more rapidly than exchanges between all group-members in a group. When strong ties between two actors are established, social control is aimed at the maintenance of these interpersonal relationships instead of compliance with group obligations, which may decrease group effectiveness.

Third, cohesive networks enhance social support. Close-knit networks exchange more affective and instrumental support (Heaney and Israel, 2008), which in turn is related to individual wellbeing. In studies, social support has also been associated with lower levels of work stress and work strain, although overall results remain inconclusive (Viswesvaran et al., 1999).

Fourth, networks provide a sense of social identity (Podolny and Baron, 1997). According to the Social Identity Theory (Tajfel and Turner, 1979) a person's selfimage is connected to the image of the group to which he or she belongs; individuals define themselves in terms of their group-membership and ascribe typical characteristics of the group to themselves. For social identification to occur, groupmembership has to be made salient (Van Knippenberg, 2000); especially closed and cohesive networks are deemed to facilitate social identity (Jones and Volpe, 2011). Social Identity Theory forms the basis for organizational identification, which is related to feelings of attachment and loyalty to the organization (Mael and Tetrick, 1992). Several studies have investigated the relationship between social networks and organizational identification focusing on individual's networks (see Jones and Volpe, 2011 for an overview). Bartels et al. (2007) found that determinants of identification with the organization as a whole differ from the determinants of employees' identification with lower organizational levels. The climate of internal communication was especially important for the identification with the lower levels of the organization. Perceived external prestige appeared more important for employees' identification with the overall organization.

How are these mechanisms of social networks related to the treatment of residents with dementia in long-term care? We expect social networks to be related to behaviour of nursing staff both directly and indirectly. First, we expect that the existence of boundary-crossing ties between nursing staff and relatives/ acquaintances of residents will affect behaviour of nursing staff towards residents 
Beek, A.P.A. van, Wagner, C., Frijters, D.H.M., Ribbe, M.W., Groenewegen, P.P. The ties that bind? Social networks of nursing staff and staff's behaviour towards residents with dementia. Social Networks: 2013, 35(3), 347-356

directly because these contacts provide information on the background and habits of residents. Information about elderly residents, that those residents cannot provide themselves due to their dementia.

In addition, we argue that boundary-crossing ties will also guide the appropriate treatment of residents because they enhance trust.

We will explain this reasoning through the concept of embeddedness as described by Granovetter (1985, 2005) and Uzzi (1997). Uzzi (1997) noted that socially embedded ties in exchange networks are often formed through referrals by third-parties or previous personal relationships (Uzzi, 1997). Trust is seen as a primary feature of these embedded ties (Granovetter, 1985, 2005) and described by Uzzi (1997) as: 'the belief that an exchange partner would not act in self-interest at another's expense'. When untrustworthy behaviour is detected, this not only affects further exchanges between two actors, but information about untrustworthy behaviour will also spread to others in the extended network that is shared by actors (Uzzi, 1997), increasing the chances of punishment (Granovetter, 2005).

Boundary-crossing ties of nursing staff with relatives or acquaintances of residents represent the manner in which staff members and residents are embedded in the community outside the organization. If these ties exist, we expect that staff members will be less likely to act in self-interest at the expense of the resident. For instance by treating residents poorly or by rushing aspects of care to be able to spend time chatting to colleagues.

Furthermore, when a boundary-crossing tie exists, untrustworthy behaviour of staff members will not only affect the relationship with the resident. It will also influence the relationship between the staff member and family/acquaintances of this resident outside the long-term care facility, giving these third parties opportunities to sanction unwanted behaviour (control) (Buskens and Raub, 2002). Notably, an important distinction from the original (economic) exchanges described by Uzzi (1997) and Granovetter (1985, 2005) is that there exists no equal exchange relationship between staff members and residents with dementia, making residents with dementia extremely vulnerable. For this reason, we expect that the possibilities of control by third parties become even more important in this setting.

Based on these expectations we define the following general hypothesis:

H1. On dementia units with more boundary-crossing networks residents are given a better treatment.

Second, we expect that boundary-crossing and communication networks will indirectly influence behaviour through staff members' identification with the organization. We specify our expectations on the level of individual staff members and at unitlevel.

First, we expect that boundary-crossing ties will increase identification with the organization as third parties will regard staff members as representatives of the facility, making staff's membership to the facility salient (see Van Knippenberg, 2000). Thus, we expect a relationship between boundary-crossing ties and organizational identification at the level of individual nursing staff. We believe that for nursing staff identification with the facility is especially important, as public opinion on quality of long-term care in the Netherlands has been mainly based on media attention to adverse events in facilities. Less attention has been paid to the quality of care of individual units or holdings to which facilities may belong. In addition, we expect that staff members' organizational identification is also 
Beek, A.P.A. van, Wagner, C., Frijters, D.H.M., Ribbe, M.W., Groenewegen, P.P. The ties that bind? Social networks of nursing staff and staff's behaviour towards residents with dementia. Social Networks: 2013, 35(3), 347-356

influenced by the density of staff's communication networks as interpersonal relations affect a person's attitudes about the attractiveness of the group and their orientation towards group-membership (Hechter, 1987; West et al., 1999; Friedkin, 2004). Following Bartels et al. (2007), we expect that boundary-crossing ties are especially important for organizational identification as they are related to the reputation (or external prestige) of staff members in the community. When no boundarycrossing tie exists, we expect that the density of internal communication networks becomes more important for organizational identification.

Consequently, we hypothesize an interaction effect of boundary-crossing ties at the individual level and density of communication networks at unit-level, where density of communication networks becomes more important when no boundary-crossing ties exist.

H2. Boundary-crossing ties increase staff members' identification with the facility. H3. Dense communication networks of nursing staff increase staff members' identification with the facility, particularly when no boundary-crossing ties exist. Organizational identification motivates group-members to work in the group's interest (Van Knippenberg, 2000; Haslam, 2004). We expect that organizational identification is positively related to work motivation which results in a better treatment of residents in dementia units. Work motivation is deemed to be especially important for nursing staff, as they often seem to choose their jobs on intrinsic values such as recognition, contacts with residents and task content over instrumental rewards such as salary (Tummers et al., 2002). We hypothesize that this relationship between organizational identification, work motivation and behaviour exists at the level of individual staff members but will affect the treatment of all residents of the unit (as staff members work for all residents of an unit).

H4. Organizational identification results in higher work motivation.

H5. Residents are given better treatment on dementia units with more motivated nursing staff.

In summary, this study investigates social networks of nursing staff and attitudes and behaviour of nursing staff at individual and group-level. It can best be described using the micro-macro scheme that was introduced by Coleman (1990) and is often used in sociology (Raub et al., 2011). The structure of the theoretical framework, and our hypotheses, are presented in Fig. 1. At the macro-level, we study the relationship between social networks of nursing staff and the treatment of residents. To understand this macro-relationship we investigate how social networks affect organizational identification and work motivation on the micro-level, and study how work motivation is related to the treatment of residents of the unit on macro-level.

\section{Methods.}

\subsection{Design and ethical considerations}

The study was guided by a cross-sectional design. Data were collected between October 2002 and June 2003 in 37 long-term care dementia units in the Netherlands. Each unit was visited by two researchers during three days. During these days, questionnaires were distributed among nursing staff of the units and the behaviour towards residents was systematically observed. According to Dutch regulation no approval of an ethics committee for this study was necessary, as no intervention was investigated and data were not directly collected from residents. Written informed consent from legal representatives of residents was obtained. In addition, client 
Beek, A.P.A. van, Wagner, C., Frijters, D.H.M., Ribbe, M.W., Groenewegen, P.P. The ties that bind? Social networks of nursing staff and staff's behaviour towards residents with dementia. Social Networks: 2013, 35(3), 347-356

councils of the participating facilities were informed of the study in advance and anonymity and confidentiality for residents and nursing staff were guaranteed.

\subsection{Setting}

In the Netherlands, long-term dementia care is provided in psychogeriatric units in nursing homes and residential homes (Hoek et al., 2000). Residents who live in these psychogeriatric units receive multidisciplinary care and often share bedrooms. In addition, residential homes provide dementia care in psychogeriatric group projects. These group projects also provide multidisciplinary care and aim to delay or prevent admission of residents to a nursing home. Residents who attend group projects live in their own apartments in the facility, but spend most of their day in a small group setting.

For this study, a convenience sample of facilities was recruited in four regions in the Netherlands; data were collected in one unit in each facility. Participating units consisted of 26 psychogeriatric units: 16 units in nursing homes and 10 units in residential homes. In addition, 11 group projects in residential homes also took part. Group projects provided care to an average of 12 residents compared to 28 residents on psychogeriatric units in nursing homes. Analyses showed that the 37 units in the study did not differ from psychogeriatric units in general in the Netherlands in terms of the psychosocial and somatic care requirements of residents (Mathijssen et al., 2004).

\subsection{Social networks of nursing staff}

We individualized the questionnaires for each unit by presenting the names of all staff. To measure communication networks we asked the following question:

'Please report for each colleague how often you speak to him or her about your work or things that happen at work' (Krackhardt and Hanson, 1993). Frequency of contacts was presented in five categories ranging from a few times a day (5) to less than two times a month/never (0). Communication networks were analyzed with the UCINET software package (Borgatti et al., 2006). First, responses of individual members of nursing staff were symmetrized (Hanneman and Riddle, 2005; Kossinets, 2006), coding a tie between two members of nursing staff when at least one indicated a relation with the other. Second, the answers were dichotomized (Borgatti et al., 2006; Hanneman and Riddle, 2005) into at least once a week and rare (twice a month or less). Third, density was computed as a measure of the general level of cohesion of the network (Hanneman and Riddle, 2005).

For boundary-crossing networks we were interested in the ties between nursing staff and relatives or acquaintances of residents in the community. We collected information on these networks with a question based upon the work of Milgram (1967), known as the 'small world problem' (1967), that later became popularly known as the 'six degrees of separation experiment' (Watts, 2004).

\section{[FIGURE 1].}

Individual staff members were asked if they knew residents of their units through others and how many ties (steps) existed between them and this resident. We asked the following question: 'Please think randomly of a resident of this unit, for instance by choosing a resident whose surname starts with the same capital letter as yours. 
Beek, A.P.A. van, Wagner, C., Frijters, D.H.M., Ribbe, M.W., Groenewegen, P.P. The ties that bind? Social networks of nursing staff and staff's behaviour towards residents with dementia. Social Networks: 2013, 35(3), 347-356

How many intervening steps of people you know are necessary to arrive at this resident?' Two examples were provided to clarify the question.

Example 1. 'I did not know resident Y. before she was admitted to this unit. However, I went to school with her daughter.'

Example 2. 'My father knew resident X. when they were younger; they played billiards together. Resident $\mathrm{X}$. visited my parents once in a while.' In both examples there is one intervening step between the resident and the member of nursing staff. For this study, the presence of boundary-crossing ties between residents and nursing staff was important, the number of intervening steps was less important. For this reason, answers were dichotomized for each member of nursing staff with a score of one representing a boundary-crossing tie (regardless of the number of intervening steps) and a score of zero representing no boundary-crossing ties with residents.

\subsection{Organizational identification and motivation}

Organizational identification was measured in two ways: identification with the dementia unit and identification with the facility.

Identification with the unit was measured by an adaptation of the Dutch version of Mael and Ashforth's organizational identification scale (Ashforth and Mael, 1989; Mael and Tetrick, 1992; Van Knippenberg et al., 2001). This scale consists of six items. Answers are scored from 1 (totally disagree) to 5 (totally agree). For this study, the name of the unit was inserted into each item. Examples of items are 'When someone criticizes < name unit>, I feel personally offended' 'I'm very interested about others' opinion of <name unit>'.

For the total score, scores of all items were summed and then divided by six. The higher the score the more nursing staff identified with the unit. Cronbach's alpha of the scale in this study was 0.69 . In addition to these questions for the unit, nursing staff were asked with one overall question if the answers applied in the same way for the facility the unit belonged to. Answers on this item were scored on a scale from 1 (to a far lesser extent) to 5 (to a far more extent). The score of this last question was used as the main variable for identification with the organization in our analyses. Intrinsic work motivation was measured with six items derived from a scale developed by Warr et al. (1979). Examples of items are: 'I feel a sense of personal satisfaction when I do my job well' and 'My opinion of myself decreases when I do this job badly'. Answers are scored from 1 (totally disagree) to 5 (totally agree). For the total score, scores of all items were summed and then divided by six, a higher score representing a higher work motivation. Cronbach's alpha of the scale in this study was 0.71 .

\subsection{Treatment of residents by nursing staff}

For the observations, an observation-list of 32 items was used that focused on different aspects of care for residents. The observation-list was derived from a list that was based on the aspects of quality of care defined by Rantz et al. (1998). Each item was scored on a five-point scale, with 5 representing the most positive score. Six items of the observation-list were related to the behaviour of nursing staff towards residents: starting a friendly conversation with residents, taking sufficient time for residents, calling residents by their name, treating residents with respect, actively caring for residents, and residents and nursing staff smiling at each other and seeming at ease with each other. 
Beek, A.P.A. van, Wagner, C., Frijters, D.H.M., Ribbe, M.W., Groenewegen, P.P. The ties that bind? Social networks of nursing staff and staff's behaviour towards residents with dementia. Social Networks: 2013, 35(3), 347-356

The observation-list was completed at three times, one observation on each day of data-collection. Observation-times represented three important moments of care: morning (around $9.00 \mathrm{~h}$ ), dinnertime (around $12.00 \mathrm{~h}$ ), and the afternoon (around $15.30 \mathrm{~h}$ ). The times of observation were not known to the units in advance. After an observation-period of twenty to thirty minutes, both researchers individually completed the list and, afterwards, discussed their findings. A total of 15 researchers carried out the observations on the 37 units. One researcher (and first author of this article) observed all the observation-moments $(N=111)$, each time accompanied by one of the 14 other researchers. A score for each item was computed based on the average score of the two researchers over all three observation-moments. Interobserver reliability of the separate items varied between 0.65 and 0.78 (based on Pearson's correlation coefficient), with a mean of 0.74 . Cronbach's alpha of the six items was 0.84 .

\section{DATA ANALYSIS.}

To test the hypotheses, data were analyzed in several steps distinguishing between analyses on macro-level and micro-level.

First, the correlation (Pearson's correlation coefficient) between boundary-crossing networks of nursing staff and the treatment of residents at the level of units was studied (H1). Second, we looked at the relationship between social networks of nursing staff, organizational identification and work motivation. The existence of boundary-crossing ties, organizational identification and motivation were all measured at the individual level. Density of communication networks was measured at unit-level. For this reason we carried out multilevel analyses (Snijders and Bosker, 1999; Leyland and Groenewegen, 2003) in MLwiN in which individual and unit variables could be combined. In addition, multilevel analyses show how much variance in outcomes can be ascribed to the unit and to individual staff members. Two separate models were analyzed, each with two levels: units (level 2) and nursing staff on these units (level 1). In model 1, the relationship between boundary-crossing networks, density of communication networks and organizational identification was studied (H2 and H3). Model 2 investigated the relation between organizational identification and work motivation (H4).

In the multilevel analyses it was first investigated how organizational identification was influenced by characteristics of nursing staff and structural aspects of the units (type of care setting and number of nursing staff). Second, boundary-crossing and communication networks were entered into the model. Boundary-crossing networks were first entered into the analyses on the level of individual staff members; density of communication networks, measured on unit level, was then entered into the model as a crosslevel interaction, as it was expected that communication networks among nursing staff become more important when no boundarycrossing ties exist. For work motivation (model 2) the analyses were repeated. In addition, organizational identification was added to the model.

Finally, we studied the relationship between work motivation and the treatment of residents at unit-level (based on Pearson's correlation coefficient; H5).

\section{Results.}


Beek, A.P.A. van, Wagner, C., Frijters, D.H.M., Ribbe, M.W., Groenewegen, P.P. The ties that bind? Social networks of nursing staff and staff's behaviour towards residents with dementia. Social Networks: 2013, 35(3), 347-356

A total of 474 nursing staff completed the questionnaire of this study. This was $55 \%$ of all 861 nursing staff in the units. The majority of nursing staff consisted of women (95\%), with an average age of 38 years (ranging between 16 and 63). Nursing staff mostly worked part-time (77\%) and the vast majority held a permanent position (89\%).

The question on communication networks was answered by 380 staff members. Two units were excluded for analyses due to a response rate of less than $15 \%$. The response percentage on the remaining 35 units varied between $18 \%$ and $100 \%$ per unit with an average response rate of 53\%. In psychogeriatric units in nursing homes and residential homes the average response rate was $45 \%$.

In group projects the average response rate was $71 \%$. Response rates were negatively related to the size of the units. On units with more nursing staff, response rates on communication networks were lower (correlation between the number of nursing staff and the response rate on communication networks was $-0.61, p<0.001$ ). The average density of the communication networks was 0.52 , varying between 0.22 and 1.0 for the participating units.

Density of communication networks was also significantly related to the number of nursing staff in the unit $(0.698, p<0.01)$. When we controlled for the average response on the social network questions, the relationship between the number of nursing staff and the density of communication networks of the units remained significant $(p<0.01)$.

The question on boundary crossing networks was answered by 391 nursing staff in the 37 units (average response rate 45\%). A boundary crossing tie was mentioned by $44 \%$ of the nursing staff, varying between $0 \%$ and $100 \%$ of nursing staff on the units. On average, $35 \%$ of nursing staff in psychogeriatric units in nursing homes mentioned a boundary crossing tie. For psychogeriatric units in residential homes this was $48 \%$; for group projects it was $53 \%$.

H1 Direct relationship between boundary-crossing networks of nursing staff and treatment of residents.

Table 1 gives an overview of the correlations between boundarycrossing networks of nursing staff and the observed treatment of residents in the 37 units. In units with more boundary-crossing ties, nursing staff treated residents with more respect, and nursing staff and residents seemed more at ease with each other $(p<0.05)$. Furthermore, boundary-crossing ties were related to the number of times nursing staff started a friendly conversation with residents and the amount of time they actively cared for residents $(p<0.10)$. The different items to measure treatment of residents were also positively related to each other. For instance, on units where nursing staff more frequently started a friendly conversation with residents, they also took more time for residents and treated residents with more respect. The results support Hypothesis 1.

H2 and H3 Relationship between social networks and organizational identification of nursing staff.

Next, the relationship between boundary-crossing networks, density of communication networks and nursing staff's organizational identification was studied. Average identification with the facility was $3.0(\mathrm{sd}=0.81)$ on a scale from 1 to $5(n=457)$. Table 2 presents the relationship between characteristics of nursing staff, structural aspects of the units, social networks and identification with the facility for nursing staff of 35 units. Identification with the facility varied 
Beek, A.P.A. van, Wagner, C., Frijters, D.H.M., Ribbe, M.W., Groenewegen, P.P. The ties that bind? Social networks of nursing staff and staff's behaviour towards residents with dementia. Social Networks: 2013, 35(3), 347-356

significantly between staff members. There was also significant variance between units (see variance components for the empty model in Table 2). Of the variance $16 \%$ could be ascribed to differences on the level of the units (as presented by the Intra Class Correlation in the empty model in Table 2). Identification with the facility was not related to characteristics of the nursing staff in our sample (see Step 1, Table 2). However, it was related to structural aspects of the units. On larger units nursing staff identified less with the facility (Step 2, Table 2). This relationship between size of the units and identification ceased to exist when

\section{[TABLE 1][TABLE 2][TABLE 3].}

boundary-crossing networks and communication networks were entered into the model. No main effect for boundary-crossing networks was found. Yet, we did find an interaction effect of boundary-crossing networks and communication networks. When there were no boundary-crossing ties, the density of communication networks of staff in the unit was positively related to identification with the facility (Step 3, Table 2).

The results do not support Hypothesis 2. We found no main effect for boundarycrossing networks and identification with the facility. Yet, we found a cross-level interaction effect of boundarycrossing ties and communication networks for organizational identification. The results support Hypothesis 3.

H4 Relationship between organizational identification and work motivation of nursing staff.

Average work motivation was $4.0(\mathrm{sd}=0.47)$ on a scale from 1 to $5(n=468)$. Table 3 shows that motivation varied significantly between individual members of nursing staff. No significant variation between the units was found (see variance components for the empty model in Table 3). For work motivation, $4 \%$ of the variance could be ascribed to differences on the level of the units (as presented by the Intra Class Correlation in the empty model in Table 3).

Identical to the analyses for organizational identification, it was first investigated how motivation was influenced by characteristics of nursing staff and structural aspects of the units. We found that older nursing staff was more motivated (Step 1, Table 3). Work motivation was not related to structural aspects of the units or the social networks of nursing staff (Step 2, Table 3). However, nursing staff that identified more with the facility were more motivated to provide better care (Step 3, Table 3). The results thus support Hypothesis 4.

\section{[TABLE 4].}

H5 Relationship between work motivation and treatment of residents.

Finally, scores of work motivation were aggregated to the unit-level to investigate whether motivation was related to the treatment of residents of the units. For this, the percentage of nursing staff that scored higher than average $(>4.0)$ on the scale for work motivation was assessed. These percentages of nursing staff with a high work motivation varied between $25 \%$ and $100 \%$ between the units with an average of $58 \%$.

The percentage of highly motivated nursing staff related positively to the treatment of residents in the units (Table 4). In units with more motivated nursing staff, nursing 
Beek, A.P.A. van, Wagner, C., Frijters, D.H.M., Ribbe, M.W., Groenewegen, P.P. The ties that bind? Social networks of nursing staff and staff's behaviour towards residents with dementia. Social Networks: 2013, 35(3), 347-356

staff smiled at residents more often and seemed more at ease with residents ( $p<$ $0.05)$, and more often started a friendly conversation with residents $(p<0.10)$. The results support Hypothesis 5.

\section{Discussion.}

This study is the first to examine the relationship between social networks of nursing staff and behaviour of nursing staff towards elderly residents with dementia. On units where nursing staff reported more contacts with relatives and acquaintances of residents (boundary-crossing ties), nursing staff treated residents more often with respect and approached residents in a friendly manner both by being at ease and by starting friendly conversations with residents. Social networks also indirectly affected the treatment of residents. Communication networks of nursing staff were positively related to staff's identification with the facility when no boundary-crossing ties existed. Organizational identification in turn was related to work motivation of nursing staff which, aggregated to unit-level, proved to be positively related to the treatment of residents of the unit. These results largely supported our hypotheses. Several characteristics of nursing staff and characteristics of the units that could influence the relationship between social networks and organizational identification and work motivation were taken into account. Only one characteristic of nursing staff was found to be related to the dependent variables. Older nursing staff was more motivated to provide good care. More nursing staff on the unit was found to be negatively related to identification with the facility. However, this relationship between size of the unit and identification ceased to exist when social networks were entered into the model.

The results of this study should be interpreted with caution.

First, the response rates on the social network measures were limited. The question regarding communication networks had a response rate of 53\%, after we excluded two units with very poor response. We found that response rates were lower in units with more nursing staff. Evidently it is easier to answer questions for a limited group of colleagues than for a larger group. Kossinets (2006) argues that non-response in social network surveys can be partially balanced out by reciprocal nominations of actors. If A does not fill in the network questionnaire but $\mathrm{B}$ and $\mathrm{C}$ of the same network describe their interactions with A, information about the social network of A is still available. In the analyses data were symmetrized, coding a tie between members of nursing staff when at least one staff member indicated a tie with this colleague. Through this, information was gained on the communication networks of those who did not complete the questionnaire. Furthermore, when low response rate leads to smaller numbers, the Empirical Bayes Estimation used in the multilevel analyses shrinks the estimates to the general mean, which results in a conservative approach.

The question on boundary-crossing networks was answered by $44 \%$ of nursing staff. It is not known whether the remaining nursing staff had no boundary-crossing tie (as this answer was not provided structurally with the question), or if they did not understand the question due to how it was constructed. The question used to obtain boundary-crossing information was relatively complex, not only asking after the presence of a boundary-crossing tie but also asking after the number of intervening 
Beek, A.P.A. van, Wagner, C., Frijters, D.H.M., Ribbe, M.W., Groenewegen, P.P. The ties that bind? Social networks of nursing staff and staff's behaviour towards residents with dementia. Social Networks: 2013, 35(3), 347-356

steps. Perhaps response rates would be higher if the latter part of the question was omitted, as it would make the question easier to understand.

Dementia care in the Netherlands is provided by an educationally diverse nursing staff and, due to the growing number of older people that need extensive care, often staff with a low education level is employed. As this is the first study to address networks between nursing staff and family and acquaintances of residents in longterm care, it is impossible to compare our findings or response rates to other studies. To address our response problem, we performed additional analyses in which all missing values were recoded into value 0 (no boundary-crossing tie exists). The findings of these analyses did not differ from the results that are presented in this article. Nevertheless, the limited response on both social network questions is an important limitation of this study. Further studies should focus on methods to obtain more complete social network data of nursing staff.

Second, the study was guided by a cross-sectional design in which several outcomes were used. Overall, reliability of the scales used for organizational identification, intrinsic work motivation and behaviour towards residents with dementia was sufficient. Yet, several limitations can be identified. Organizational identification was measured in two ways: identification with the dementia unit and identification with the facility. The score of this last item - that measured deviations from the identification with the unit - was used as the main variable for identification with the organization in our analyses. This measure has to our knowledge not been used before. Further research is needed to see if similar results may be obtained in other settings. Cronbach's alpha for intrinsic work motivation was 0.71 . Although not very high, this is comparable to other studies in the Netherlands in which the scale was used. For instance, Janssen et al. (1999) reported a Cronbach's alpha of 0.70 in their study of nurses in a general hospital.

The behaviour of nursing staff towards residents with dementia was observed during three days on each unit by two researchers.

Although the observations show sufficient interrater reliability, there were differences in how the researchers interpreted the interaction between nursing staff and residents. In addition, with the results of this study, it is impossible to determine whether treatment of residents differed over time in the units and whether nursing staff reacted to the presence of the researchers. However, precautions were taken to optimize the reliability of the findings.

One researcher observed all 37 units on all occasions. The observations were carried out at three different moments which were not known to the nursing staff in advance and researchers were asked to report possible reactivity effects of nursing staff if they became aware of them. Overall, reactivity of nursing staff to the researchers was found to be limited, which is consistent with earlier research by

Schnelle et al. (2006), who found no effects of reactivity of nursing staff when using observations to assess quality of care.

Third, although we corrected for several characteristics at staffand unit-level, we expect that the relationship between social networks and identity may also be contingent on other characteristics (for instance trust in management and team leadership) that were not part of this study. Furthermore, the relationship may also be mediated by other mechanisms which we discussed in the theoretical background but were not part of this study, such as social support. The power of our multilevel analyses was restricted to 35 units at the highest level of analyses and only a limited 
Beek, A.P.A. van, Wagner, C., Frijters, D.H.M., Ribbe, M.W., Groenewegen, P.P. The ties that bind? Social networks of nursing staff and staff's behaviour towards residents with dementia. Social Networks: 2013, 35(3), 347-356

amount of unit variables could be taken into account. Consequently, our analyses are not extensive and it is important that future research identifies which other aspects and mechanisms mediate the relationship between networks, identification, work motivation and behaviour of staff in long-term care. An important characteristic which we would like to mention separately is the experienced workload of nursing staff as it may be expected that especially workload is related to the time nursing staff spend interacting with residents. For the 35 units, the average workload was not extremely high (mean $=2.9$ on a scale from 1 to 5 ; $s d=0.60$ ). Although we found a weak correlation between workload and the density of communication networks ( $p=$ 0.10 ), we found no significant correlation between workload and organizational identification or motivation. Workload was significantly correlated to nursing staff taking sufficient time for residents $(p<0.05)$ and the number of times nursing staff called residents by their name $(p<0.10)$. Interestingly, those two aspects of the treatment of residents were not significantly correlated to either the existence of boundarycrossing ties or to the work motivation of nursing staff. These results show that workload is important when studying the treatment of residents in long-term care, but seems to affect the treatment of residents through different mechanisms and on different aspects.

In this study, we focused on the relationship between social networks of nursing staff and the treatment of residents with dementia at the macro-level by studying the attitudes and behaviour of staff at the micro-level. For this, we followed the micromacro scheme that is often used in sociological studies (Coleman, 1990). Raub et al. (2011) state that: "micro-macro models aim at explanations of macro-outcomes and at incorporating macroconditions in the explanation rather than at explaining individual behaviour as such". In the next paragraphs, we will discuss our findings in view of this micro-macro explanation.

Boundary-crossing ties of nursing staff with relatives/ acquaintances of residents were investigated using a question based on the small-world problem. Although the accuracy of small world chains by respondents is questioned (Killworth et al., 2006) and the response in our study was limited, the results indicate that this type of question is suited to gain insight in indirect ties of nursing staff with residents who are extremely vulnerable. Our definition of boundary-crossing ties was closely linked to the concept of embeddedness as described by Granovetter (1985, 2005), and Uzzi (1997). We proposed two mechanisms through which boundary-crossing ties affect treatment of residents on the macro-level: (1) contacts provide information and (2) boundary-crossing ties enhance trust and provide opportunities for control. In this study a positive relationship was found between the existence of boundary-crossing ties and the treatment of residents in dementia units. However, due to our study design we cannot unravel if this result is due to information exchange or to the trust/control mechanism. Yet, the findings of this study indicate that when a boundary-crossing tie exists a staff member is more likely to treat all residents of the unit better, not only the resident with whom the boundary-crossing tie exists. This may be ascribed to the fact that the boundary-crossing ties in our study indeed can be seen as a measure of social embeddedness of staff and residents in the community, which decreases the inclination of staff to act in self-interest at the cost of residents. For this mechanism, we focused on the behaviour of nursing staff and not on the behaviour of residents as they, due to their dementia, are the most vulnerable party in the exchange relationship and are not able to maintain their social networks 
Beek, A.P.A. van, Wagner, C., Frijters, D.H.M., Ribbe, M.W., Groenewegen, P.P. The ties that bind? Social networks of nursing staff and staff's behaviour towards residents with dementia. Social Networks: 2013, 35(3), 347-356

themselves. Although we found a positive relationship between boundary-crossing ties and the treatment of residents by nursing staff, our findings must be seen as a first attempt to unravel how embedded ties may influence quality of care in healthcare settings. For instance, in our study no attention was paid to the fact that information about untrustworthy behaviour of relatives and acquaintances of residents may also find its way to the dementia unit and may affect the behaviour of nursing staff towards particular residents.

Furthermore, we have no information of values and norms that are shared between staff members, residents, and third parties outside the organization. Baker and Faulkner (2009) name this cultural embeddedness, and they use the term 'double embeddedness' to include both structural (social) and cultural embeddedness. Our research is also closely linked to the concept of job embeddedness as constructed by Mitchell et al. (2001) to explain employee turnover. Job embeddedness not only incorporates connections to colleagues and organizations, but also includes connections of employees with the community and people in the community (Mitchell et al., 2001). All in all, the findings implicate that it may be beneficial for long-term care facilities to employ nursing staff who have ties with relatives and acquaintances of residents outside the organization, as this positively affects the treatment of residents. This may be achieved by recruiting staff from the community where residents originate from.

On the micro-level, we found a relationship between networks, organizational identification and work motivation. The results show that the communication network between nursing staff of a unit is important for organizational identification, especially when few or no boundary-crossing ties exist. No main effect for boundarycrossing networks at the individual-level was found. We hypothesized that relatives and acquaintances of residents would regard nursing staff as representatives of the facility, which would make their group-membership to the facility salient. Yet, our results indicate that organizational identification is not so much the product of the salience of individual group-membership, but is shaped by closely-knit communication ties with other staff members at unit-level in combination with the existence of boundary-crossing networks at the individual-level. This finding does not correspond with earlier findings of Bartels et al. (2007) who found that internal communication patterns were especially important for identification with the lower levels of the organization and external prestige was important for identification with the organization as a whole.

Perhaps our findings are a result of our view on group-membership. Implicitly, we assumed that nursing staff would regard residents as members of the facility. Yet, when nursing staff do not regard residents as members of the same group, contacts with residents will make staff's membership to the organization salient all the time and contacts with outsiders will become less important. This may explain why no main effect for boundary-crossing ties on organizational identification was found. It may also explain why especially communication ties with staff members seem to be important for identification with the facility, as only staff members are seen as the fellow members of the group.

Two more aspects of our study need to be discussed. First, we investigated the existence of boundary-crossing and communication ties of nursing staff and not the strength of these ties. It may be expected that very strong ties may hinder the treatment of residents. 
Beek, A.P.A. van, Wagner, C., Frijters, D.H.M., Ribbe, M.W., Groenewegen, P.P. The ties that bind? Social networks of nursing staff and staff's behaviour towards residents with dementia. Social Networks: 2013, 35(3), 347-356

For instance, in our observations, we incidentally noted that strong ties may also result in nursing staff talking to each other during care, instead of interacting with residents. When ties with relatives are strong, this may lead to less criticism and an unwillingness of relatives to impose sanctions. This is the weakness of strong ties that Flache and Macy (1996) addressed in their study. Although, we found no indication for a negative relationship between the density of communication ties and the treatment of residents, such a negative relationship may exist if the ties are particularly strong. It is important that further research focuses on this possible adverse effect of strong ties.

Second, we based our study on the assumption that a good treatment of residents is an overall aim of the facility. Thus, we expected that resident-oriented behaviour of staff coincides with formal group-norms. Moments of observation, especially morning care and dinner-time, were specifically chosen because some interaction with residents was part of the job. In this regard, noncompliance with organizational norms was not a subject of this investigation. Yet, it would be interesting to study how behaviour of nursing staff towards residents is influenced by group-norms and under which conditions nursing staff will turn against organizational rules.

Implicitly, our results emphasize an important point: to be able to provide good care to residents with dementia in longterm care it is important that organizational norms and protocols focus on the interaction with residents.

The results show that social networks of nursing staff play an important role in care processes in long-term dementia care. The findings indicate that care may be improved by facilitating contacts between nursing staff and relatives of residents with dementia in the community. Although we did not look at the actual presence of relatives in the unit, our results tie in with other studies that underline the importance of contacts with relatives of residents in long-term care (for instance Fisher et al., 2008). Furthermore, care may be improved by facilitating informal communication among staff members, especially when no or few contacts between nursing staff and relatives of residents exist. Recent studies (Schnelle et al., 2004; Kim et al., 2009) have demonstrated that higher staffing levels are related to better quality of care in nursing homes. Although it is difficult for long-term care facilities to increase manpower because of costs, results of this study indicate that care may also be improved by changing extra- and intra-organizational communication patterns. Further research is needed to study how social networks of nursing staff affect other aspects of care.

\section{ACKNOWLEDGEMENTS.}

The study was supported by a grant from the Netherlands Organisation for Scientific Research (NWO) and the Netherlands Organisation for Health Research and Development (ZonMw). The authors would like to thank Prof. Dr. Henk Flap of Utrecht University for his help with the development of the social network questions and their subsequent analysis and Peter Spreeuwenberg of the Netherlands Institute of health services research for his help with the multilevel analyses. The authors also thank an anonymous reviewer of this journal for her/his very helpful comments on a previous draft. 
Beek, A.P.A. van, Wagner, C., Frijters, D.H.M., Ribbe, M.W., Groenewegen, P.P. The ties that bind? Social networks of nursing staff and staff's behaviour towards residents with dementia. Social Networks: 2013, 35(3), 347-356

\section{REFERENCES.}

Anderson, R.A., Issel, L.M., McDaniel Jr., R.R., 2003. Nursing homes as complex adaptive systems: relationship between management practice and resident outcomes.

Nursing Research 53, 12-21.

Ashforth, B.E., Mael, F., 1989. Social identity theory and the organization. Academy of Management Review 14, 20-39.

Baker, W., Faulkner, R.R., 2009. Social capital, double embeddedness and mechanisms of stability and change. American Behavioral Scientist 52, 1531-1555.

Bartels, J., Pruyn, A., de Jong, M., Joustra, I., 2007. Multiple organizational identification levels and the impact of perceived external prestige and communication climate. Journal of Organizational Behavior 28, 173-190.

Bluestein, D., Latham-Bach, P., 2007. Working with families in long-term care. Journal of the American Medical Directors Association 8, 265-270.

Borgatti, S.P., Everett, M.G., Freeman, L.C., 2006. UCINET for Windows: Software for Social Network Analysis. Version 6.10. Analytic Technologies, Harvard, MA, available at: http://www.analytictech.com/ucinet Boscart, V.M., 2009. A communication intervention for nursing staff in chronic care.

Journal of Advanced Nursing 65, 1823-1832.

Burt, R.S., 1992. The social structure of competition. In: Nohria, N., Eccles, R.G.

(Eds.), Networks and Organizations, Structure, Form and Action. Harvard Business School Press, Boston, MA, pp. 57-91.

Buskens, V., Raub, W., 2002. Embedded trust: control and learning. In: Thye, S.R., Lawler E.J. (Eds.), Group Cohesion, Trust and Solidarity, 19. Advances in Group Processes, pp. 167-202.

Coleman, J.S., 1990. Foundations of Social Theory. Belknap Press of Harvard University Press, Cambridge.

Christenson, A.M., Buchanan, J.A., Houlihan, D., 2011. Command use and compliance in staff communication with elderly residents of long-term care facilities.

Behavior Therapy 42, 47-58.

Evans, C.R., Dion, K.L., 1991. Group cohesion and performance: a meta analysis.

Small Group Research 22, 175-186.

Festinger, L., 1950. Informal social communication. Psychological Review 57, 271-282.

Fisher, C., Lindhorst, H., Matthews, T., Munroe, D.J., Paulin, D., Scott, D., 2008. Nursing staff attitudes and behaviours regarding family presence in the hospital setting.

Journal of Advanced Nursing 64, 615-624.

Flache, A., Macy, M.W., 1996. The weakness of strong ties: collective action failure in a highly cohesive group. Journal of Mathematical Sociology 21, 3-28.

Flap, H., Völker, B., 2001. Goal specific social capital and job satisfaction: effects of different types of networks on instrumental and social aspects of work. Social Networks 23, 297320.

Friedkin, N.E., 2004. Social cohesion. Annual Review of Sociology 30, 409- 425.

Graneheim, U.H., Norberg, A., Jansson, L., 2001. Interaction relating to privacy, identity, autonomy and security. An observational study focusing on a woman with dementia and 'behavioural disturbances' and on her care providers. Journal of Advanced Nursing 36, 256-265.

Granovetter, M.S., 1973. The strength of weak ties. American Journal of Sociology 78, 1360-1380.

Granovetter, M., 1985. Economic action and social structure: the problem of embeddedness. American Journal of Sociology 91, 481-510.

Granovetter, M., 2005. The impact of social structure on economic outcomes. Journal of Economic Perspectives 19, 33-50.

Hanneman, R.A., Riddle, M., 2005. Introduction to Social Network Methods. University of California, Riverside. 
Beek, A.P.A. van, Wagner, C., Frijters, D.H.M., Ribbe, M.W., Groenewegen, P.P. The ties that bind? Social networks of nursing staff and staff's behaviour towards residents with dementia. Social Networks: 2013, 35(3), 347-356

Haslam, S.A., 2004. Psychology in Organizations: The Social Identity Approach. Sage Publications, London.

Heaney, C.A., Israel, B.A., 2008. Social networks and social support. In: Glanz, K., Rimer, B.K., Viswanath, K. (Eds.), Health Behavior and Health Education: Theory, Research and Practice. , 4th ed. John Wiley and Sons, San Francisco, CA, pp.

189-210.

Hechter, M., 1987. The Principles of Group Solidarity. University of California Press, Berkely/London.

Hewison, A., 1995. Nurse's power in interactions with patients. Journal of Advanced Nursing 21, 75-82.

Hoek, J.F., Penninx, B.W.J.H., Ligthart, G.J., Ribbe, M.W., 2000. Healthcare for older persons, a country profile: The Netherlands. Journal of the American Geriatrics Society 48, 214-217.

Janssen, P.P.M., De Jonge, J., Bakker, A.B., 1999. Specific determinants of intrinsic work motivation, burnout and turnover intentions: a study among nurses.

Journal of Advanced Nursing 29, 1360-1369.

Jones, C., Volpe, E.H., 2011. Organizational identification: extending our understanding of social identities through social networks. Journal of Organizational Behavior 32, 413-434.

Killworth, P.D., McCarty, C., Bernard, H.R., House, M., 2006. The accuracy of small world chains in social networks. Social Networks 28, 85-96.

Kim, H., Kovner, C., Harrington, C., Greene, W., Mezey, M., 2009. A panel data analysis of the relationship of nursing home staffing levels \& standards to regulatory deficiencies. Journal of Gerontology 64B, 269-278.

Kossinets, G., 2006. Effects of missing data in social networks. Social Networks 28, 247268.

Krackhardt, D., Hanson, J.R., 1993. Informal networks: the company behind the chart. Harvard Business Review 71, 104-111.

Leyland, A.H., Groenewegen, P.P., 2003. Multilevel modelling and public health policy. Scandinavian Journal of Public Health 31, 267-274.

Lothian, K., Philp, I., 2001. Maintaining the dignity and autonomy of older people in the healthcare setting. British Medical Journal 322, 668-670.

Lott, A.J., Lott, B.E., 1965. Group cohesiveness as interpersonal attraction: a review of relationships with antecedent and consequent variables. Psychological Bulletin 64, 259309.

Mael, F.A., Tetrick, L.E., 1992. Identifying organizational identification. Educational and Psychological Measurement 52, 813-824.

Mathijssen, S.W., Van der Kwartel, A.J.J., Pepels, C.G.M., Winkel, E.G.J., Barnhard, M.C., Van der Velde, F., 2004. Brancherapport Care 2000-2003. Ministerie van

Volksgezondheid, Welzijn en Sport, Den Haag.

Milgram, S., 1967. The small world problem. Psychology Today 1, 60-67.

Mitchell, T.R., Holtom, B.C., Lee, T.W., Sablynski, C.J., Erez, M., 2001. Why people stay: using job embeddedness to predict voluntary turnover. Academy of Management Journal $44,1102-1121$.

Nelson, H.W., 2000. Injustice and conflict in nursing homes: towards advocacy and exchange. Journal of Aging Studies 14, 39-61.

Perry, J., Galloway, S., Bottorff, J.L., Nixon, S., 2005. Nurse-patient communication in dementia: improving the odds. Journal of Gerontological Nursing 31, 43-52.

Podolny, J.M., Baron, J.N., 1997. Resources and relationships: social networks and mobility in the workplace. American Sociological Review 62, 673-693.

Pursey, A., Luker, K., 1995. Attitudes and stereotypes: nurses' work with older people. Journal of Advanced Nursing 22, 547-555.

Rantz, M.J., Mehr, D.R., Popejoy, L., Zqygart-Stauffacher, M., Hicks, L.L., Grando, V., Conn, V.S., Porter, R., Scott, J., Maas, M., 1998. Nursing home care quality: a multidimensional theoretical model. Journal of Nursing Care Quality 12, 30-46.

Raub, W., Buskens, V., Van Assen, M.A.L.M., 2011. Micro-macro links and microfoundations in sociology. Journal of Mathematical Sociology 35, 1-25.

Reagans, R., Zuckerman, E.W., 2001. Networks, diversity, and productivity: the social capital of corporate R\&D teams. Organization Science 12, 502-517. 
Beek, A.P.A. van, Wagner, C., Frijters, D.H.M., Ribbe, M.W., Groenewegen, P.P. The ties that bind? Social networks of nursing staff and staff's behaviour towards residents with dementia. Social Networks: 2013, 35(3), 347-356

Rundqvist, E.M., Severinsson, E.I., 1999. Caring relationships with patients suffering from dementia - an interview study. Journal of Advanced Nursing 29, 800-807.

Seashore, S.E., 1954. Group Cohesiveness in the Industrial Work Group. University of Michigan, Ann Arbor, MI. Schnelle, J.F., Simmons, S.F., Harrington, C., Cadogan, M., Garcia, E., Bates-Jensen, B., 2004. Relationship of nursing home staffing to quality of care. Health Services Research 29, 225-250.

Schnelle, J.F., Ouslander, J.G., Simmons, S.F., 2006. Observations of nursing home care quality: does care change when observed? Journal of the American Medical Directors Association 7, 541-544.

Scott, J.R., Schenkman, M., Moore, L., Vojir, C., Connelly, R., Pratt, M., et al., 2004. Exploring nursing home staff's perceptions of communication and leadership to facilitate quality improvement. Journal of Nursing Care Quality 19, 242-252.

Snijders, T.A.B., Bosker, R.J., 1999. Multilevel Analysis: An Introduction to Basic and Advanced Multilevel Modelling. Sage Publications, London.

Tajel, H., Turner, J.C., 1979. An integrative theory of intergroup conflict. In: Austin, W.G., Worchel, S. (Eds.), The Social Psychology of Intergroup Relations. Brooks/Cole, Montery, CA.

Tummers, G.E.R., Landeweerd, J.A., Van Merode, G.G., 2002. Organization, work and work reaction: a study of the relationship between organizational aspects of nursing and nurses' work characteristics and work-reaction. Scandinavian Journal of Caring Sciences 16, 5258.

Uzzi, B., 1997. Social structure and competition in interfirm networks: the paradox of embeddedness. Administrative Science Quarterly 42, 35-67.

Van Bilsen, P.M.A., Otten, D.D., Kerkstra, A., 1998. De interactie tussen verzorgenden en dementerende ouderen in het verpleeghuis; een literatuuroverzicht (Interaction between nursing staff and elderly with dementia in the nursing home: a review of literature). Verpleegkunde 2, 109-127.

Van Knippenberg, D., 2000. Work motivation and performance: a social identity perspective. Applied Psychology: An International Review 49, 357-371.

Van Knippenberg, A., Van Knippenberg, B., Van Knippenberg, C., Van Knippenberg, D., 2001. Identificatie met de organisatie: Een meetinstrument (Identification with the organization: a measurement scale). Gedrag \& Organisatie 14, 67-73.

Viswesvaran, C., Sanchez, J.I., Fisher, J., 1999. The role of social support in the process of work stress: a meta-analysis. Journal of Vocational Behavior 54, 314-334.

Warr, P.B., Cook, J.C., Wall, P.B., 1979. Scaling for the measurement of some attitudes and aspects of psychological well-being. Journal of Occupational Psychology 52, 129-148.

Watts, D.J., 2004. Six Degrees: The Science of a Connected Age. Vintage Random House, London, England.

West, E., Barron, D.N., Dowsett, J., Newton, J.N., 1999. Hierarchies and cliques in the social networks of health care professionals: implications for the design of dissemination strategies. Social Science and Medicine 48, 633-646. 
Beek, A.P.A. van, Wagner, C., Frijters, D.H.M., Ribbe, M.W., Groenewegen, P.P. The ties that bind? Social networks of nursing staff and staff's behaviour towards residents with dementia. Social Networks: 2013, 35(3), 347-356

\section{TABLES}

Fig. 1. The expected relationship between social networks of nursing staff and the treatment of residents.

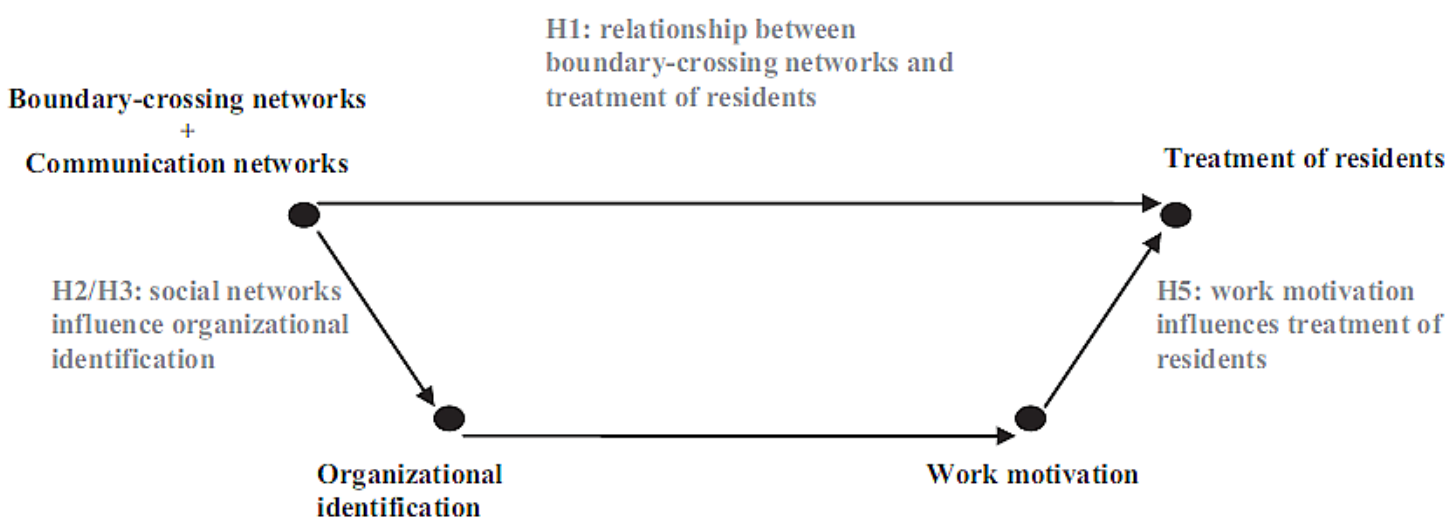

H4: organizational identification

influences work motivation

Table 1

Correlations between social networks of nursing staff and the treatment of residents on the units $(N-37)$.

\begin{tabular}{|c|c|c|c|c|c|c|}
\hline & $\begin{array}{l}\text { Nursing staff } \\
\text { starts friendly } \\
\text { conversation }\end{array}$ & $\begin{array}{l}\text { Nursing staff } \\
\text { takes sufficient } \\
\text { time }\end{array}$ & $\begin{array}{l}\text { Nursing staff call } \\
\text { residents by their } \\
\text { name }\end{array}$ & $\begin{array}{l}\text { Nursing staff treats } \\
\text { residents with } \\
\text { respect }\end{array}$ & $\begin{array}{l}\text { Nursing staff and } \\
\text { residents seem at } \\
\text { ease with each other }\end{array}$ & $\begin{array}{l}\text { Nursing staff } \\
\text { actively care for } \\
\text { residents }\end{array}$ \\
\hline $\begin{array}{l}\text { \% of nursing staff with a boundary-crossing } \\
\text { network }\end{array}$ & $0.314^{*}$ & 0.268 & 0.267 & $0.350^{\prime \prime}$ & $0.342^{\prime \prime}$ & $0.287^{\circ}$ \\
\hline Nursing staff starts friendly conversation & & $0.771^{\cdots}$ & $0.605^{\cdots}$ & $0.727^{\cdots}$ & $0.771^{\prime *}$ & $0.512 \cdots$ \\
\hline Nursing staff take sufficient time & & & $0.648^{\cdots \cdots}$ & $0.739 \cdots$ & $0.773^{\cdots *}$ & $0.595 \cdots$ \\
\hline Nursing staff call residents by their name & & & & $0.785^{\cdots *}$ & $0.665^{\cdots *}$ & $0.363^{*}$ \\
\hline Nursing staff treats residents with respect & & & & & $0.779^{\cdots}$ & $0.592 \cdots$ \\
\hline $\begin{array}{l}\text { Nursing staff and residents seem at ease } \\
\text { with each other }\end{array}$ & & & & & & $0.569 \cdots$ \\
\hline
\end{tabular}

- Correlation is significant at the 0.10 level.

- Correlation is significant at the 0.05 level.

-.. Correlation is significant at the 0.01 level. 
Beek, A.P.A. van, Wagner, C., Frijters, D.H.M., Ribbe, M.W., Groenewegen, P.P. The ties that bind? Social networks of nursing staff and staff's behaviour towards residents with dementia.

Social Networks: 2013, 35(3), 347-356

Table 2

Results of the multi-level analyses for organizational identification (range 1-5) of nursing staff $(N-373)$ on the units $(N-35)$.

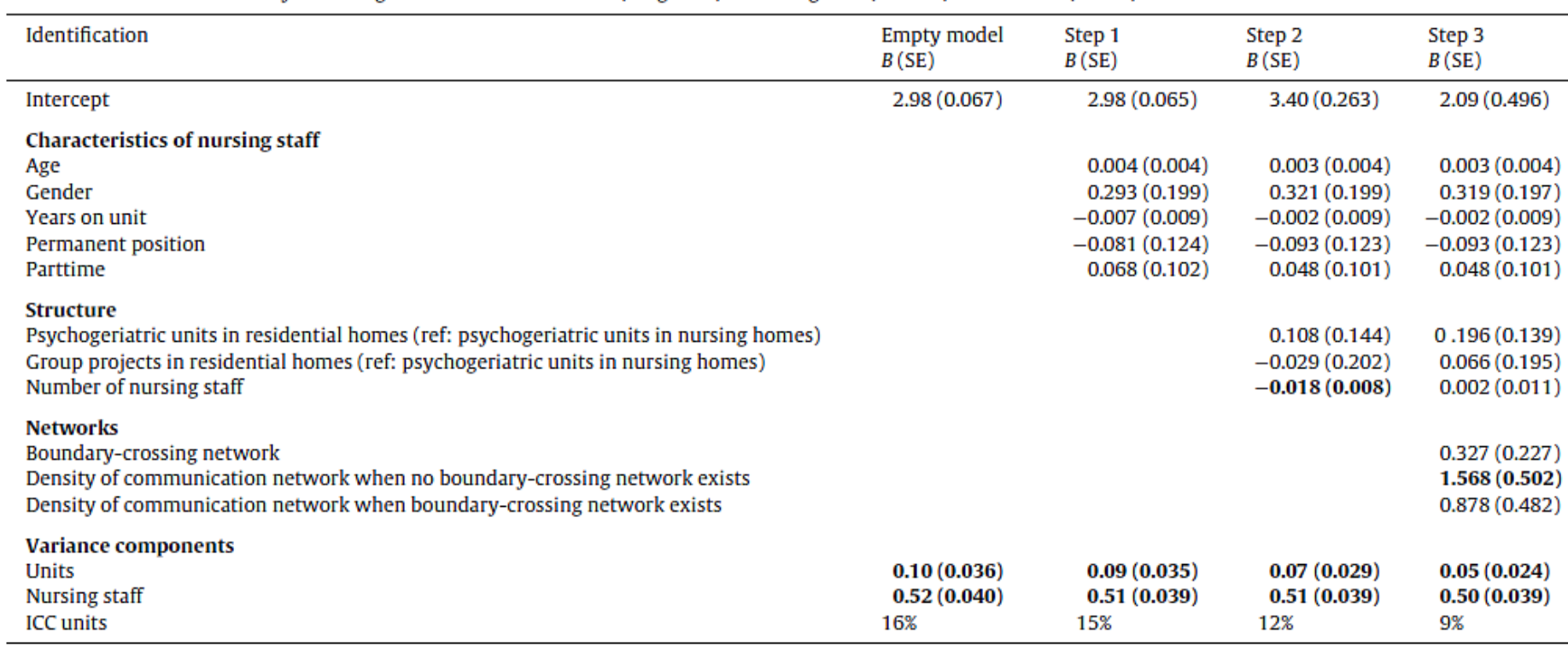

Bold font indicates a significant association at $p<0.05$.

Table 3

Results of the multi-level analyses for work motivation (range 1-5) of nursing staff $(N-373)$ on the units $(N-35)$

\begin{tabular}{|c|c|c|c|c|}
\hline Motivation & $\begin{array}{l}\text { Empty model: } \\
B(\mathrm{SE})\end{array}$ & $\begin{array}{l}\text { Step } 1 \\
B \text { (SE) }\end{array}$ & $\begin{array}{l}\text { Step } 2 \\
B(\mathrm{SE})\end{array}$ & $\begin{array}{l}\text { Step } 3 \\
B(\mathrm{SE})\end{array}$ \\
\hline Intercept & $4.01(0.027)$ & $4.01(0.025)$ & $3.98(0.112)$ & $3.88(0.245)$ \\
\hline $\begin{array}{l}\text { Characteristics of nursing staff } \\
\text { Age } \\
\text { Gender } \\
\text { Years on unit } \\
\text { Permanent position } \\
\text { Parttime }\end{array}$ & & $\begin{array}{r}0.007(0.002) \\
0.155(0.115) \\
-0.006(0.005) \\
-0.006(0.070) \\
-0.038(0.059)\end{array}$ & $\begin{array}{r}\mathbf{0 . 0 0 7}(\mathbf{0 . 0 0 2}) \\
0.152(0.115) \\
-0.006(0.005) \\
-0.009(0.071) \\
-0.038(0.059)\end{array}$ & $\begin{array}{r}\mathbf{0 . 0 0 6}(\mathbf{0 . 0 0 2}) \\
0.114(0.114) \\
-0.007(0.005) \\
0.000(0.070) \\
-0.044(0.058)\end{array}$ \\
\hline $\begin{array}{l}\text { Structure } \\
\text { Psychogeriatric units in residential homes (ref: psychogeriatric units in nursing homes) } \\
\text { Group projects in residential homes (ref: psychogeriatric units in nursing homes) } \\
\text { Number of nursing staff }\end{array}$ & & & $\begin{array}{r}0.054(0.060) \\
-0.036(0.084) \\
0.001(0.003)\end{array}$ & $\begin{array}{r}0.016(0.065) \\
-0.073(0.092) \\
-0.002(0.005)\end{array}$ \\
\hline $\begin{array}{l}\text { Networks } \\
\text { Boundary-crossing network } \\
\text { Density of communication network when no boundary-crossing network exists } \\
\text { Density of communication network when boundary-crossing network exists }\end{array}$ & & & & $\begin{array}{r}0.062(0.129) \\
-0.190(0.256) \\
-0.241(0.241)\end{array}$ \\
\hline Identification with the facility & & & & $0.085(0.030)$ \\
\hline $\begin{array}{l}\text { Variance components } \\
\text { Units } \\
\text { Nursing staff } \\
\text { ICC units }\end{array}$ & $\begin{array}{l}0.007(0.005) \\
0.181(0.014) \\
4 \%\end{array}$ & $\begin{array}{l}0.005(0.005) \\
0.178(\mathbf{0 . 0 1 4}) \\
3 \%\end{array}$ & $\begin{array}{l}0.004(0.005) \\
0.177(0.014) \\
2 \%\end{array}$ & $\begin{array}{l}0.004(0.005) \\
0.177(0.014) \\
2 \%\end{array}$ \\
\hline
\end{tabular}

Bold font indicates a significant association at $p<0.05$. 
Beek, A.P.A. van, Wagner, C., Frijters, D.H.M., Ribbe, M.W., Groenewegen, P.P. The ties that bind? Social networks of nursing staff and staff's behaviour towards residents with dementia. Social Networks: 2013, 35(3), 347-356

\section{Table 4}

Correlations between motivation of nursing staff and the treatment of residents on the units $(N-37)$.

\begin{tabular}{ll}
\hline & Work motivation \\
\hline Nursing staff start friendly conversation & $0.282^{*}$ \\
Nursing staff take sufficient time & 0.261 \\
Nursing staff call residents by their name & 0.181 \\
Nursing staff treat residents with respect & 0.212 \\
Nursing staff and residents seem at ease with each other & $0.330^{*}$ \\
Nursing staff actively care for residents & 0.190 \\
\hline
\end{tabular}

\footnotetext{
- Correlation is significant at the 0.10 level.

" Correlation is significant at the 0.05 level.
} 